\title{
Building the capacity of faith-based organizations to promote mutual monogamy in South Africa
}

\author{
Waimar Tun \\ Population Council \\ Nathi Sohaba \\ Unathi Malinzi \\ Matthew Nqono \\ Osborne Mzilikazi
}

See next page for additional authors

Follow this and additional works at: https://knowledgecommons.popcouncil.org/departments_sbsr-hiv

Part of the Demography, Population, and Ecology Commons, Family, Life Course, and Society

Commons, International Public Health Commons, and the Medicine and Health Commons

How does access to this work benefit you? Let us know!

\section{Recommended Citation}

Tun, Waimar, Nathi Sohaba, Unathi Malinzi, Bp. Matthew Nqono, Pstr. Osborne Mzilikazi, Pstr. Bonisiwa Mgujulwa, Rev. Moses Madywabe, Mbulelo Fatyeni, and Christine Fontecchio. 2007. "Building the capacity of faith-based organizations to promote mutual monogamy in South Africa," Horizons Research Summary. Johannesburg: Population Council. 


\section{Authors}

Waimar Tun, Nathi Sohaba, Unathi Malinzi, Matthew Nqono, Osborne Mzilikazi, Bonisiwa Mgujulwa, Moses Madywabe, Mbulelo Fatyeni, and Christine Fontecchio 


\section{Building the Capacity of Faith- Based Organizations to Promote Mutual Monogamy in South Africa}

A collaborative effort between Horizons/ Population Council, South African Council of Churches, and the Eastern Cape Provincial Council of Churches, with support from USAID, successfully led to the implementation of sermons and workshops promoting mutual monogamy among church members as a way to prevent HIV. Results indicate positive changes in awareness of mutual monogamy as an HIV prevention strategy, attitudes toward and communication about mutual monogamy, and a growing recognition of the role of mutual monogamy in creating a healthy family life.

I n South Africa, where sex partnerships outside primary relationships are common even among church members, HIV prevention programs focusing on mutual monogamy (MM) are needed. Because church leaders are highly regarded by the community, they may be effective in reaching congregation members with HIV prevention messages. However, implementing programs that promote faithfulness pose

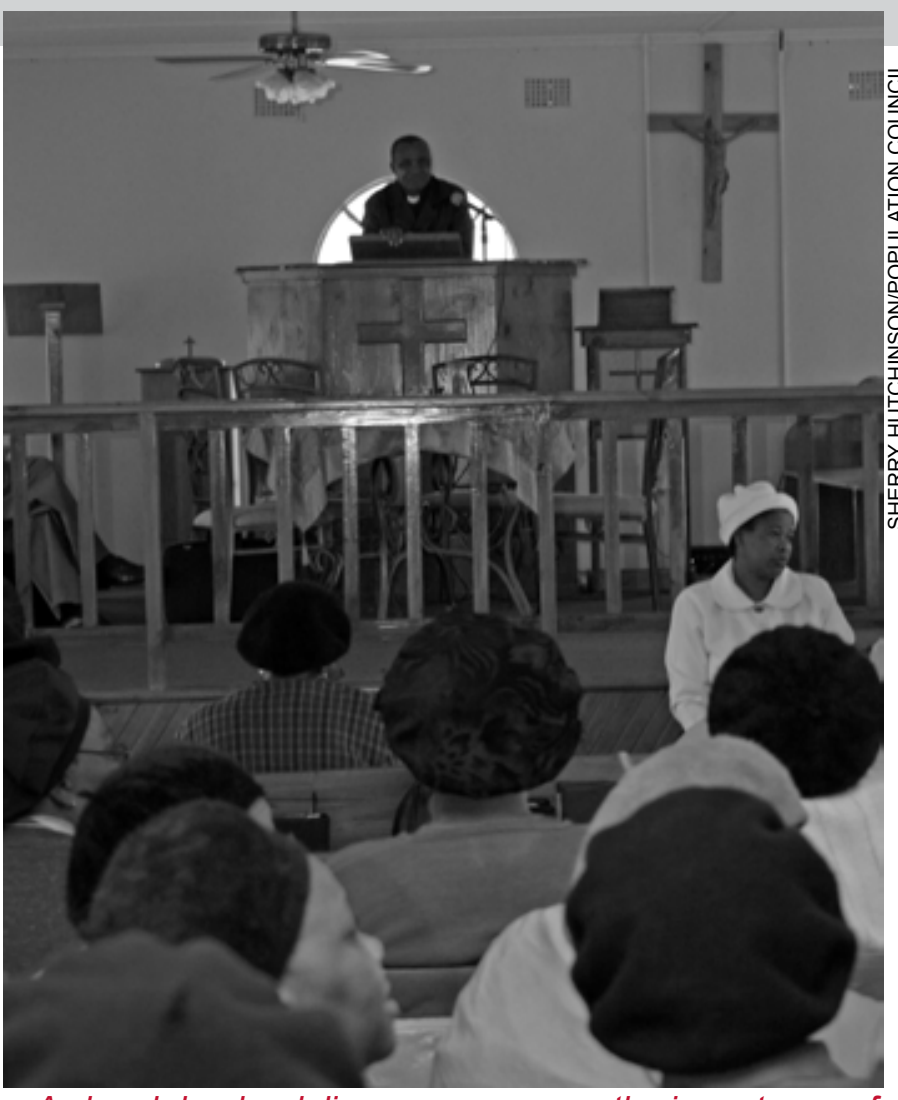

A church leader delivers a sermon on the importance of mutual monogamy to a congregation at the Uniting Presbyterian Church in Butterworth, Eastern Cape.

several challenges for FBOs and churches, such as a tendency for church leaders to avoid discussing sensitive issues like multiple sex partners as well as a lack of capacity to systematically and effectively deliver HIV prevention interventions.

To read more about this study, go to www.popcouncil.org/horizons/projects/SouthAfrica_FBOMutualMon.htm
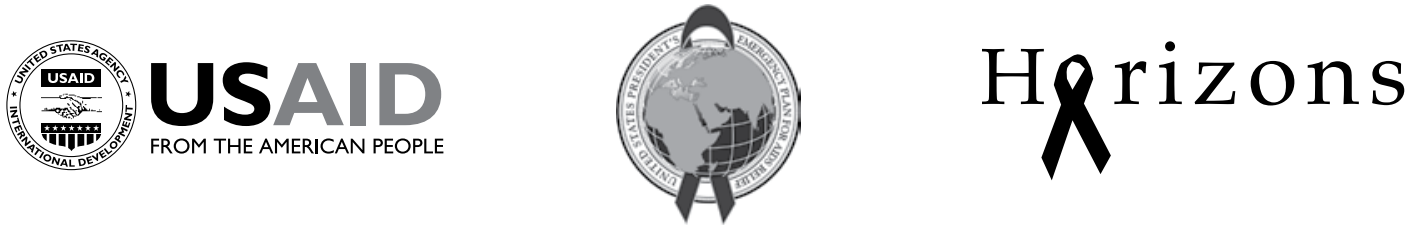
In response to a lack of research on effective strategies to promote MM, the Horizons Program, in partnership with the Eastern Cape Provincial Council of Churches and the South African Council of Churches piloted an intervention to promote MM.

The target audience for the intervention was church-going, married or co-habiting couples in the towns of Alice and Butterworth in the Eastern Cape. A curriculum, based on behavior change theory and formative research, was developed to cover topics including HIV transmission, personal relationships, gender dynamics, and couple communication. The curriculum was first used to train a group of church leaders, who then facilitated group workshops at their churches using modules from the curriculum. They also delivered sermons on the same topics to their entire congregations. In total, 18 churches participated from both areas, reaching 1,363 church members through congregation-wide sermons and 316 people (76 men and 240 women) through workshops.

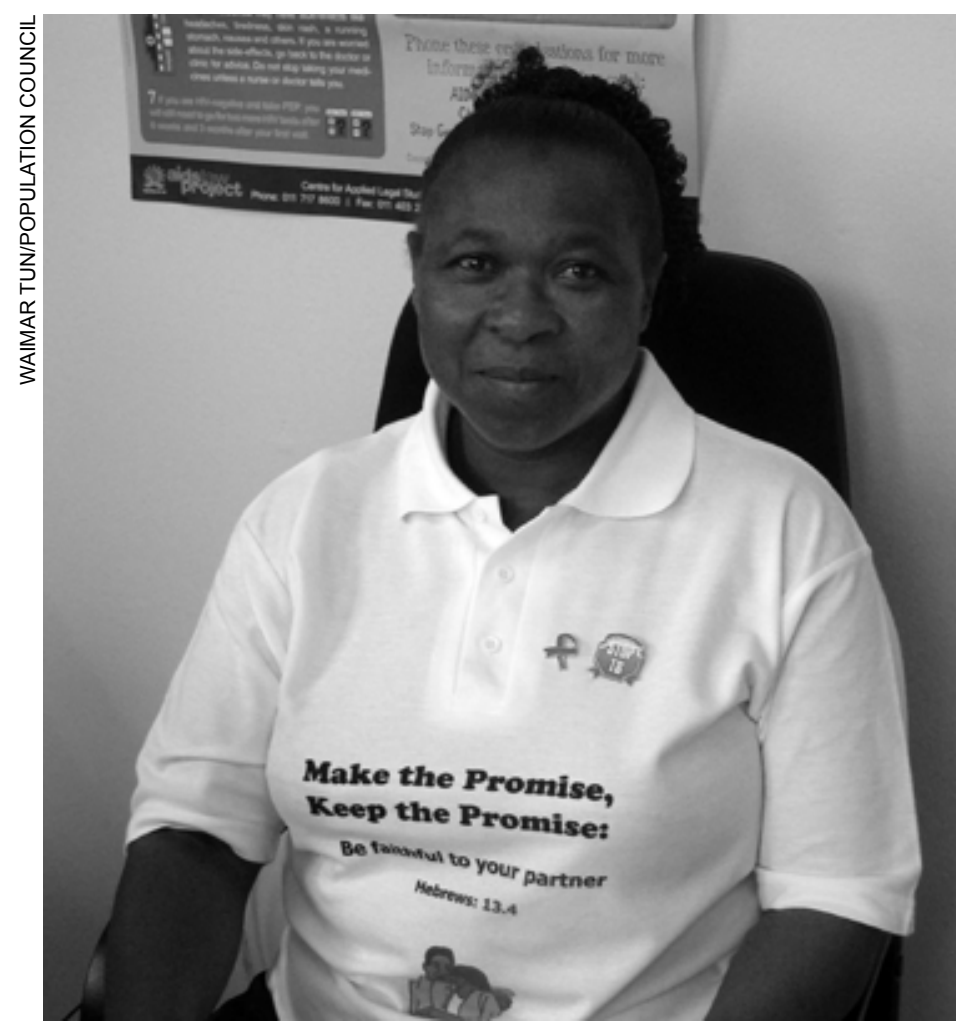

Pastor Bonisiwa Gujulwa provides counseling on mutual monogamy to couples at the Butterworth Counseling Center.
To assess the results, a survey was administered to 345 church members before and 302 church members after the 3-month pilot program. In-depth interviews with intervention participants, workshop facilitators, church leaders, and program coordinators were also conducted.

\section{Characteristics of Respondents}

- At baseline, three-quarters of the 345 respondents were female. Most respondents were between 35-54 years old, married, had lived with their spouse for more than five years, and had been sexually active in the last three months.

- At endline, 11 percent reported having no exposure to the intervention and 21 percent reported attending none of the workshops and no more than 3 sermons. For purposes of analysis, these two groups were combined to form the "little or no participation group" ( $n=96)$. Forty-four percent had attended none of the workshops but heard at least 4 sermons; 24 percent attended at least one workshop and heard at least 1 sermon. These groups were combined and categorized as the "high participation group" ( $\mathrm{n}=206)$.

\section{Key Findings}

\section{HIV knowledge}

- Knowledge that MM and consistent condom use were effective methods to prevent HIV was already high at baseline, but it increased at endline only among those with high participation in the program (see Figure 1).

\section{HIV-related stigma}

- Qualitative interviews with participants revealed that the program helped to destigmatize HIV and raise awareness of the importance of accepting those infected: 
What I liked by those sermons is that if a person is HIV positive, we have to accept him/her and love them because God loves us all as we are and a person who is HIV positive is not cursed... just sick.

\section{Gender-based violence}

- There is a trend, post-intervention, toward lower rates of physical, sexual and psychological abuse in the past three months experienced by women in the high participation group.

- Interviews with both men and women revealed that the program made them realize that abuse also includes psychological abuse:

There is abuse which we didn't really know it was abuse and that as women we have been always submissive to things and to even things that are abusive to us. My eyes were opened.

-Female

\section{Mutual monogamy}

- Extramarital relationships appear to be common in the community. At baseline and endline, nearly 70 percent of all respondents thought most men in the community have extramarital relationships; 40 percent thought so about women in the community.

- At baseline, approximately 15 percent of married or cohabiting respondents reported having another partner in the past three months besides their primary partner. Further, about one-quarter thought that their partner had another partner outside their relationship. As expected, due to the short time of the intervention, there was no difference between baseline and endline for either of these variables.

- There was also no change among respondents in perceived difficulty to practice MM; approximately 50 percent thought it was difficult to implement.

- However, those in the high participation group at endline were more likely to consider communication about MM not to be difficult and to have communicated with their partner about MM compared to respondents at baseline and those in the little/no participation group (Figure 2).

- Participants of the program also uniformly emphasized the importance of MM in creating a healthy family:

As parents, we are role models and kids will grow to be fathers as well one day, so they shouldn't think that this kind of behavior is right. So all of them [the workshops] were very important.

-Female

\section{Figure 1 Knowledge of methods of HIV prevention}

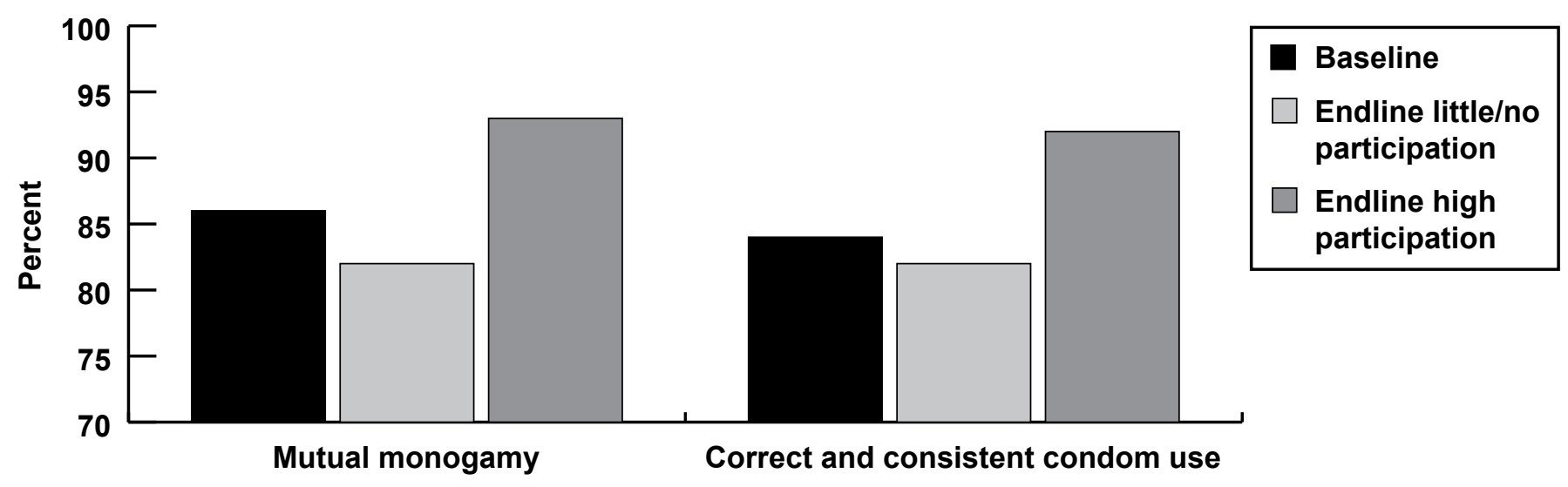

Knowledge of these methods of HIV prevention 
Figure 2 Communication about mutual monogamy

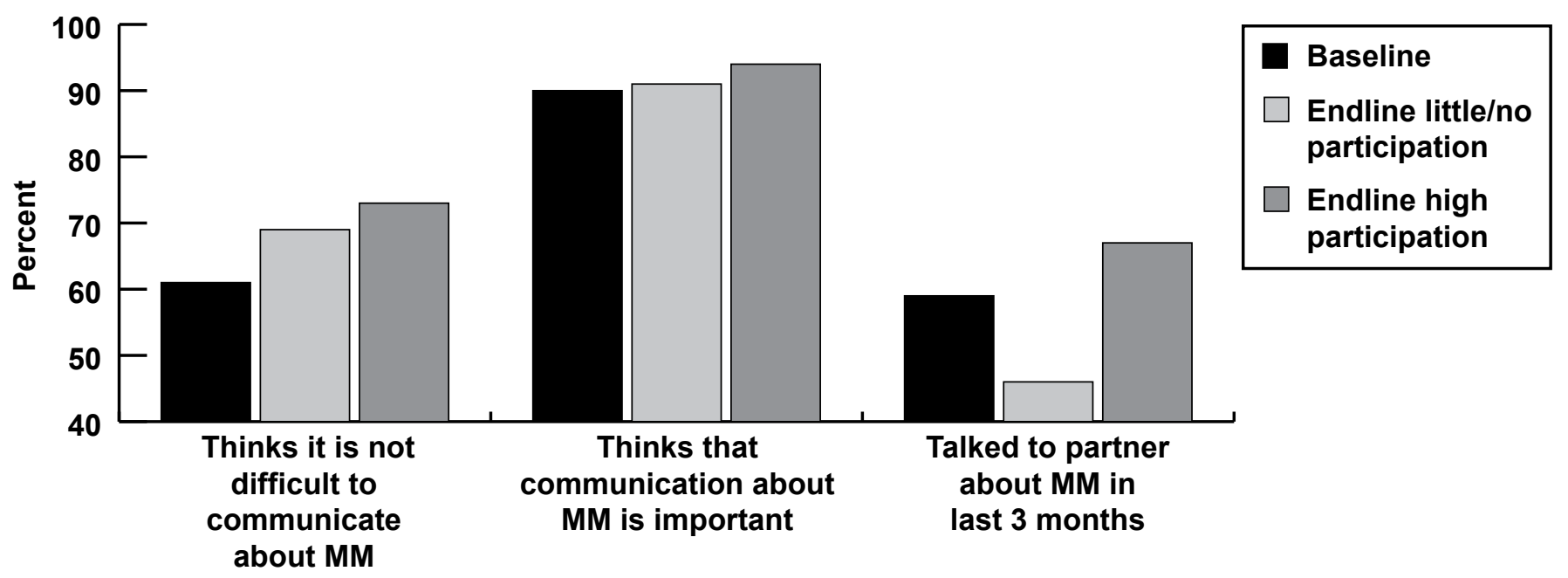

\section{Program Implications}

The pilot program was associated with some positive changes among church-goers which support the potential of FBOs to promote MM. Further research will be conducted to assess behavioral impact as the program is rolled out to additional churches in the Eastern Cape Province. $\mathbb{X}$

December 2007
Study investigators include Waimar Tun and Nathi Sohaba of Horizons/Population Council, Unathi Malinzi and Bp. Matthew Nqono of ECPCC, Pstr. Osborne Mzilikazi and Pstr. Bonisiwa Mgujulwa of Butterworth HIVIAIDS Ministries, and Rev. Moses Madywabe and Mbulelo Fatyeni of Alice Hospice.

For more information, please contact Waimar Tun (wtun@popcouncil.org) or Nathi Sohaba (nsohaba@popcouncil.org).

Suggested citation: Tun, Waimar, Nathi Sohaba, Unathi Malinzi, Bp. Matthew Nqono, Pstr. Osborne Mzilikazi, Pstr. Bonisiwa Gujulwa, Rev. Moses Madywabe, Mbulelo Fatyeni, and Christine Fontecchio. 2007. "Building the capacity of faith-based organizations to promote mutual monogamy in South Africa," Horizons Research Summary. Johannesburg: Population Council.

\section{Hqrizons $\lambda$}

Population Council/Horizons

Communications Unit

4301 Connecticut Avenue, NW

Suite 280

Washington, DC 20008

\section{Population Council}

Tel: 202-237-9400

Fax: 202-237-8410

horizons@popcouncil.org

www.popcouncil.org/horizons
This research summary is made possible by the generous support of the American people through the United States Agency for International Development (USAID) and the President's Emergency Plan for AIDS Relief under the terms of HRN-A-00-97-00012-00. The contents are the responsibility of the Horizons Program and do not necessarily reflect the views of USAID or the United States Government. 